\title{
6 Complications following preresection shunting in patients with posterior fossa tumors
}

\author{
Lauren Ostling, MD, and Corey Raffel, MD, PhD \\ Department of Neurological Surgery, University of California, San Francisco, California
}

I $\mathrm{N}$ their paper "Infratentorial complications following preresection CSF diversion in children with posterior fossa tumors," Dr. El-Gaidi and colleagues provide us with a retrospective review of their experience utilizing preoperative shunting for CSF diversion in patients with posterior fossa tumors presenting with symptomatic hydrocephalus. ${ }^{3}$ Of 301 patients who underwent CSF diversion days prior to tumor resection, 5 patients had evidence of intratumoral hemorrhage (ITH) and 2 had upward transtentorial herniation (UTH) precipitating a decline in their neurological examination. These investigators conclude that infratentorial complications following CSF diversion before resection are rare, but that the prognosis for these patients is quite poor.

While the authors state that there is no consensus on preoperative management of hydrocephalus in children with posterior fossa tumors, recent publications have advocated for early tumor removal without preresection CSF diversion, given the low requirement for permanent CSF shunt placement in these children. ${ }^{1,6,9}$ The rate of permanent CSF diversion in current studies ranges from $5 \%$ to $36 \%$. $1,2,5,6,9-11$ Avoidance of shunts is advocated by most surgeons due to risk of failure, risk of infection, and the complications presented here in this paper. Thus, current state-of-the-art therapy is to avoid placing preresection shunts, reserving placement of an external ventricular drain for situations in which glucocorticosteroids are not effective in relieving symptoms or for emergency situations.

In this article, the rationale used for immediate CSF diversion in those with hydrocephalus is the lack of operating room (OR) availability and resources, the concern for infection with external ventricular drains, and the positive effect of decreased pseudomeningoceles and CSF leaks postoperatively. ${ }^{3}$ Interestingly, almost half of the patients in this paper had shunts inserted in the OR on the day of presentation or the following day. One wonders if time could have been made for early resection, given that time for placement of a shunt was available.

In regards to infection with the use of with external ventricular drains, the authors concerns here are warranted..$^{13,14}$ Infection rates with external ventricular drains have been shown to increase after 5 days of drainage. ${ }^{8}$ It appears plausible that, if OR time is difficult to obtain, an external ventricular drain could be utilized for those children with moderate to severe hydrocephalus preoperatively while waiting for an open OR time slot. It is unclear if antibiotic-impregnated catheters are available at the authors' institution, as these catheters have been shown to decrease infection rates significantly. ${ }^{14}$

While a decrease in pseudomeningoceles and CSF leaks may be true, the possible CSF leak repair appears far more manageable than the ITH or UTH they note here.

Preoperative endoscopic third ventriculostomy (ETV) was also performed in $28.9 \%$ of the patients included in this study. The routine use of preoperative ETV has been debated for children with posterior fossa tumors. However, the conclusion is essentially the same as that for shunt placement: given the low need for permanent CSF diversion and the risks associated with ETV, the potential benefit does not justify routine preoperative ETV for these patients. ${ }^{4,6,9}$

Intratumoral hemorrhage and UTH are known com- 
plications following CSF diversion in patients with posterior fossa tumors. ${ }^{71}$ Shunting and ETVs are similar in that one cannot manually regulate the amount of CSF being drained in comparison to external ventricular drains, which can have a set, small amount of CSF drained as necessary. The extremely poor prognosis for children when these complications occur appears to justify the use of an external ventricular drain, despite the authors concern for infection, as an infection can often be successfully treated. Or, as discussed previously, if an initial surgery is performed at the time of presentation, shunting can be avoided in the majority of cases. For some, an external ventricular drain is utilized when patients present with moderate to severe hydrocephalus and symptoms that are not relieved by pharmacological doses of glucocorticosteroids. External ventricular drains can be beneficial not only in managing hydrocephalus and allowing for an easier resection under less pressure, but also allow for clearance of blood products and proteinaceous debris from the CSF in the postoperative period.

Overall, this article provides a beneficial review of the complications known to occur with preoperative shunting in children with posterior fossa tumors. The data presented here, however, support adopting a new treatment protocol at their institution. Initial tumor resection at presentation, with or without the use of an external ventricular drain, is recommended.

http://thejns.org/doi/abs/10.3171/2014.9.PEDS14440

\section{References}

1. Culley DJ, Berger MS, Shaw D, Geyer R: An analysis of factors determining the need for ventriculoperitoneal shunts after posterior fossa tumor surgery in children. Neurosurgery 34:402-408, 1994

2. Dias MS, Albright AL: Management of hydrocephalus complicating childhood posterior fossa tumors. Pediatr Neurosci 15:283-290, 1989

3. El-Gaidi MA, El-Nasr AHA, Eissa EM: Infratentorial complications following preresection CSF diversion in children with posterior fossa tumors. J Neurosurg Pediatr [epub ahead of print November 7, 2014. DOI: 10.3171/2014.8.PEDS14146]

4. Fritsch MJ, Doerner L, Kienke S, Mehdorn HM: Hydrocephalus in children with posterior fossa tumors: role of endoscopic third ventriculostomy. J Neurosurg 103 (1 Suppl):40-42, 2005

5. Gnanalingham KK, Lafuente J, Thompson D, Harkness W, Hayward R: The natural history of ventriculomegaly and tonsillar herniation in children with posterior fossa tumours - an MRI study. Pediatr Neurosurg 39:246-253, 2003

6. Gopalakrishnan CV, Dhakoji A, Menon G, Nair S: Factors predicting the need for cerebrospinal fluid diversion following posterior fossa tumor surgery in children. Pediatr Neurosurg 48:93-101, 2012

7. Hoffman HJ, Hendrick EB, Humphreys RP: Metastasis via ventriculoperitoneal shunt in patients with medulloblastoma. J Neurosurg 44:562-566, 1976

8. Mayhall CG, Archer NH, Lamb VA, Spadora AC, Baggett JW, Ward JD, et al: Ventriculostomy-related infections. A prospective epidemiologic study. N Engl J Med 310:553559,1984

9. Morelli D, Pirotte B, Lubansu A, Detemmerman D, Aeby A, Fricx C, et al: Persistent hydrocephalus after early surgical management of posterior fossa tumors in children: is routine preoperative endoscopic third ventriculostomy justified? J Neurosurg 103 (3 Suppl):247-252, 2005

10. Muzumdar D, Deshpande A, Kumar R, Sharma A, Goel N, Dange N, et al: Medulloblastoma in childhood-King Edward Memorial hospital surgical experience and review: comparative analysis of the case series of 365 patients. $\mathbf{J}$ Pediatr Neurosci 6 (Suppl 1):S78-S85, 2011

11. Sainte-Rose C, Cinalli G, Roux FE, Maixner R, Chumas PD, Mansour M, et al: Management of hydrocephalus in pediatric patients with posterior fossa tumors: the role of endoscopic third ventriculostomy. J Neurosurg 95:791-797, 2001

12. Santhanam R, Balasubramaniam A, Chandramouli BA: Fatal intratumoral hemorrhage in posterior fossa tumors following ventriculoperitoneal shunt. J Clin Neurosci 16:135-137, 2009

13. Sonabend A, Korenfeld Y, Crisman C, Badjatia N, Mayer SA, Connolly ES Jr: Prevention of ventriculostomy-related infections with prophylactic antibiotics and antibiotic coated external ventricular drains: a systematic review. Neurosurgery 68:996-1005, 2011

14. Zabramski JM, Whiting D, Darouiche RO, Horner TG, Olson $\mathrm{J}$, Robertson C, et al: Efficacy of antimicrobial-impregnated external ventricular drain catheters: a prospective, randomized, controlledtrial. J Neurosurg 98:725-730, 2003

\section{Response}

\section{Mohamed Ali El-Gaidi, MD, Ashraf Hesham Abou El-Nasr, MD, and Ehab Mohamed Eissa, MD}

\section{Department of Neurosurgery, Kasr Al-Aini Medical School, Cairo University, Cairo, Egypt}

We thank Dr. Ostling and Dr. Raffel for their thoughtful comments. We seize this opportunity to explain to the reviewers and the readers about neurosurgical practice at our institution.

Abo El-Reesh Pediatric University Hospital is a busy tertiary referral center that serves many millions of Egyptian children from all over the country. Unfortunately, primary resection of posterior fossa tumors is difficult to apply at our institution because we have the same problem as other developing countries,i.e., a very high referral rate of children with large posterior fossa tumors due to relatively late diagnosis, exceeding our tumor excision capacity and resulting in a long waiting list. ${ }^{1,3}$ Tumor resection is typically performed on an elective basis in a special, wellequipped surgical theater by senior neurosurgical staff. Conversely, most children with severe hydrocephalus have shunts inserted by neurosurgical residents on an emergency basis, and most patients are typically discharged on the 2nd day and asked to return 1 day prior to the scheduled day of definitive surgery (approximately 10-14 days later). Generalized use of external ventricular drainage (EVD) is difficult to apply at our institution, not only because of the potential risk of infection, but also because these patients require hospital admission and early surgery, unlike other forms of CSF diversion. It is worth mentioning that antibiotic-impregnated or silver-bearing EVD catheters, ${ }^{2,4}$ which have been shown to decrease infection rates significantly, are unavailable at our institution.

The current study confirms that precraniotomy CSF 
diversion (shunt placement or ETV) should not be performed "routinely" in patients with posterior fossa tumors, especially large tumors (diameter $\geq 4 \mathrm{~cm}$ ) extending close to the tentorial incisura, associated with severe hydrocephalus (subependymal permeation) and significant peritumoral edema; such patients have a higher risk of developing infratentorial complications and should be treated with corticosteroids and diuretics, insertion of an external ventricular drain set at high pressure, or earlier definitive tumor resection, rather than CSF diversion. Such an approach is to be applied in the future at our institution, and we recommend this policy in other developing countries facing the same problem.

Additional resources should be allocated to our pediatric neurosurgery center to decrease the waiting time for children with posterior fossa tumors and allow primary resection.

\section{References}

1. El-Gaidi MA: Descriptive epidemiology of pediatric intracranial neoplasms in Egypt. Pediatr Neurosurg 47:385-395, 2011

2. Fichtner J, Güresir E, Seifert V, Raabe A: Efficacy of silverbearing external ventricular drainage catheters: a retrospective analysis. Clinical article. J Neurosurg 112:840-846, 2010

3. Griwan MS, Sharma BS, Mahajan RK, Kak VK: Value of precraniotomy shunts in children with posterior fossa tumours. Childs Nerv Syst 9:462-465, 1993

4. Zabramski JM, Whiting D, Darouiche RO, Horner TG, Olson J, Robertson C, et al: Efficacy of antimicrobial impregnated external ventricular drain catheters: a prospective, randomized, controlled trial. J Neurosurg 98:725-730, 2003 